\title{
Vulnerability of London's Economy to Climate Change: Sensitivity to Production Loss
}

\author{
Douglas Crawford-Brown ${ }^{1}$, Mark Syddall ${ }^{1}$, Dabo Guan ${ }^{2}$, Jim Hall ${ }^{3}$, Jun $\mathrm{Li}^{1}$, Katie Jenkins ${ }^{3}$, \\ Rachel Beaven ${ }^{4}$
}

${ }^{1}$ Cambridge Centre for Climate Change Mitigation Research, University of Cambridge, Cambridge, UK; ${ }^{2}$ School of Earth and Environment, University of Leeds, Leeds, UK; ${ }^{3}$ Environmental Change Institute, University of Oxford, Oxford, UK; ${ }^{4}$ Cambridge Econometrics, Cambridge, UK.

Email:djc77@cam.ac.uk

Received April $4^{\text {th }}, 2013$; revised May $6^{\text {th }}, 2013$; accepted June $4^{\text {th }}, 2013$

Copyright (C) 2013 Douglas Crawford-Brown et al. This is an open access article distributed under the Creative Commons Attribution License, which permits unrestricted use, distribution, and reproduction in any medium, provided the original work is properly cited.

\begin{abstract}
A variant of the Adaptive Regional Input-Output model (ARIO) has been developed to explore the sensitivity of the London economy to loss of production capacity in sectors affected by climate change related damage. The model is designed for linking to an Event Accounting Matrix (EAM) produced by climate and engineering teams, and then follow this damage through direct and indirect losses in the economy during a recovery process that is either demand-led (in which recovery of production capacity takes place only as demand recovers) or investment-led (where recovery of production capacity can precede demand). Outputs from the model are used to assess the relative vulnerability of London's economy to production capacity (Capital stock) loss in each of the 42 economic sectors, for purposes of identifying where to most effectively allocate resources to climate change adaptation strategies or to recovery operations when used in conjunction with an EAM. Measures of impact related to GDP loss, recovery time and the ratio of indirect to direct losses are developed for these scenarios. Results show that indirect losses are a significant component of total losses, with a multiplier of between 1.3 and 2 depending on the scale of initial damage.
\end{abstract}

Keywords: Climate Change; Vulnerability; Resilience; Indirect Losses; Economic Recovery

\section{Introduction}

Assessments of the impacts of climate change on cities have traditionally focused on the initial damage from extreme weather and on the costs of lost assets, declines in service, changes in public health, etc. These initial estimates are useful both in understanding the short-term implications of damage, and in marshalling the pool of capital required for re-building after an event, including via insurance claims.

Since economies are coupled, in the sense that changes in production and consumption in one sector of the economy have follow-on effects throughout the other sectors, this initial damage may be multiplied throughout the economy. This multiplication of initial damage costs, either up or down [1-3], is usually found to be greater than 1, meaning the total detrimental economic impact on measures such as GDP, per capita GDP, or GDP growth is larger than the initial damage estimate. For smaller events, demand tends to be transferred to other business outside the locality of the disaster, so whilst individual businesses may suffer losses the net indirect effect tends to be negligible from a national perspective. But it is also possible for it be less than 1 or even reverse sign if the demand created by repair of initial damage produces a stimulus to a city's economy. Quantification of the multiplier also depends upon the assumed counter-factual, which may be a constant baseline or a steadily growing economy.

Many of the actors in an economy have little interest in the full multiplier effect, since their personal investment decisions and losses following climate damage are quite specific to their activities and the value chain in which they participate. They may have neither responsibility for nor a direct interest in, measures such as GDP that reflect the overall performance of an economy, except to the extent overall macroeconomic performance influences their own financial health. Still, macroeconomic indicators such as GDP are of interest to entities such as government which have both a responsibility for 
overall economic performance and a vested interest in aggregate measures of economic performance that serve as the tax base for current and future public sector actions.

Direct economic impacts of climate damage can be defined as the physical impacts on private and public sector assets in an economy associated with production, including the forward and backward linkages in the economy to a specific sector. Backward linkages are related to the demands going to sectors that supply the inputs for a given economic activity, expressed as the capacity of a sector $(j)$ to influence production in sector $(i)$ providing inputs to sector $(j)$ [4]. This method of understanding vulnerability to climate damage has been applied in numerous studies [5]. Forward linkages characterise the capacity of sector (i) to stimulate production in other sectors $(j)$ [4].

By contrast, indirect economic losses are defined here as those that occur in a sector $(j)$ due to damage in another sector (i) by a mechanism other than $(i)$ and $(j)$ existing in a value chain. For example, damage in one sector (i) may decrease disposable income for its employees, who then are unable to spend that income in another sector $(j)$, changing demand for the output of the good or service provided by sector $(j)$.

Additionally, disruptions to "lifelines" such as transport networks, utility services and communication services can affect production capacities through changes in the movement of labour, intermediate goods and/or final goods, including imports and exports. This can cause significant impacts in the disaster aftermath as such lifelines may be highly exposed, and as most economic transactions rely on such lifelines [6,7].

Rose [8] suggests that indirect economic damages from natural disasters may be larger than, and more significant than, direct damages for two reasons. Firstly, indirect losses can affect businesses and consumers not directly affected by the event itself, so the geographic extent of indirect losses can be larger than that of the initial damage. Secondly, indirect damages capture more fully the time-dimension of the event as they reflect additional losses occurring after the initial impact beyond the direct impacts.

The scale of indirect losses and the length of economic disruption will depend on the size of the initial damage, the structure of the economy prior to the damage, and the ability of individuals, businesses, and markets to adapt in the event aftermath, e.g. through substitution of goods, the use of inventories to meet demands, use of idle capital, changes in import-export balances, or by serving alternative markets [9]. The Economic Amplification Ratio (EAR) of an event may be significantly above 1 for large scale events [10-12]. Therefore, the inclusion of indirect economic damages is crucial for evaluating the total eco- nomic impacts of extreme weather events, and determining where government intervention may be needed to reduce that impact in support of reducing GDP loss.

The research described in this paper was developed as part of the ARCADIA project (Adaptation and Resilience in Cities: Analysis and Decision making using Integrated Assessment) which is developing new methodology for analysis of climate risks and adaptation options at a city scale. The ARCADIA analysis comprises a coupled modelling suite that 1) downscales global and regional climate to changes in weather in London (as the initial case study); 2) provides probabilistic estimates of the magnitude of extreme weather events (primarily heatwaves and floods); 3) calculates the direct, initial damage caused by these events to buildings, infrastructure, transport, production capacity and health; 4) summarises these in damage functions that reflect direct losses; and 5) uses these damage functions as input to a macroeconomic model of London's economy to estimate overall impact on GDP change through changes in production and consumption during recovery periods. Specifically, we modify the ARIO model developed by Hallegatte [11] to deal with the salient characteristics of climate-related disasters in London and the subsequent economic recovery process. The next section of this paper reviews approaches that might be adopted for economic appraisal of the indirect effects of disasters on the economy. Section 3 introduces the ARIO-ARCADIA model and explains the inputs to and outputs from the model. Section 4 applies the model to representative damaging disasters in London. The paper concludes with a discussion of limitations of the analysis and areas for further research.

Similarly, the research reported here is extended to the ToPDAd (Tool Supported Development for Regional Adaptation) project, which is developing a suite of climate and economic assessment tools for application to adaptation decisions in the energy, transport and tourism sectors of EU nations, regions and cities.

As a first step in including macroeconomic modelling into modeling of climate vulnerability, an Adaptive Regional Input-Output (ARIO) model has been developed specific at present to the London economy but extendable to any community or region where the necessary input-output tables can be provided. The current paper presents that model component (component 5 in the listing above) and uses it to explore the issues of vulnerability, resilience and recovery of London's economy by disentangling the climate and engineering aspects of climate vulnerability from the macroeconomic considerations, as outlined in Section 3. The reason for this disentangling of the contributing sciences to a complete risk assessment is recognition that ARIO might be applied in conjunction with any combination of climate and engineering models, and these climate and engineering esti- 
mates may change as the science progresses. Hence ARIO is treated in this paper as a stand-alone component of risk assessments for climate damage and examined as such. The aim of the current paper is to identify where London's economy is generally most vulnerable to damage to sectoral production capacity across any number of climate events causing the same level of initial damage, to help in identifying where limited adaptation and recovery resources might best be directed in reducing the risks of climate change.

The results are therefore a measure of the relative vulnerability of London's overall GDP (indirect plus direct losses) to a given percentage loss in production capacity in any given sector following any climate related event. The specific event causing the direct damage is not important or specified in this analysis, since the analysis begins with production loss regardless of how that is produced. The results presented here are combined by a decision maker with the results of the climate science and engineering assessments of the actual percentage loss of production capacity in each of the sectors as a consequence of specific climate events.

\section{Macroeconomic Models for Estimating Indirect Impacts}

There is a wide range of models potentially available for performing the tasks of this study, falling into three general categories: 1) input-output or I-O; 2) computable general equilibrium or CGE and 3) dynamic econometric. They differ both in the theoretical principles and analytical systems used, and in the ways in which the models are parameterised. These candidate approaches were reviewed using several criteria for understanding the ability of each approach to deliver on the aims of the research:

- The degree to which it provides predictive rather than simply explanatory power;

- The degree of disaggregation of economic sectors, especially as this relates to decisions by specific actors in the London economy;

- The ability to model non-equilibrium conditions in an economy;

- The ease of obtaining reliable data on which to parameterise the model;

- The degree to which the model is, or can be created to be, open access so stakeholders in the study can see how results were obtained, and reproduce these if desired;

- The ease of interpretation of results, and the extent to which those results can be related to specific decision criteria by stakeholders;

- The computational resources required;

- The degree to which it allows endogenous calcula- tions of changes in macroeconomic performance as economies evolve in structure, wages change, prices change, etc.

The dynamic econometric models avoid the significant problem of the computable general equilibrium models of assuming the economy is in equilibrium and positing a rational, representative agent, assumptions that are not true generally and especially during the disaster recovery period. Hence the dynamic econometric models are to be preferred over CGE, and provide the most complete description of post-event recovery of the economy. However, both the CGE and dynamic econometric models have significantly larger data and computational resource requirements than the I-O model, and are less open to external review.

Realistic analysis of natural disasters and the recovery process requires practical analysis of the mechanisms of damage and the timescales over which recovery takes place. The I-O model lends itself to this type of analysis because many of the factors of damage and recovery are specified exogenously. The model is also, relatively speaking, computationally inexpensive so lends itself to doing multiple runs as part of a risk analysis. As a result, the process was to 1) perform calculations of the evolution of the macroeconomy of London, using the MDM model executed by Cambridge Econometrics; 2) use these results to produce the technical coefficients matrix (described later) forming the basis of the I-O model and 3) to then assess impacts of changes in demand and production capacity on London's economy using the I-O model.

An implicit assumption here is that the damage following a climate event changes the level of production and demand in the economic sectors, but not the overall structure of the economy. There is an additional implicit assumption that prices of goods and services remain constant during the recovery period rather than being driven significantly by changes in demand. If structure or prices were to change significantly, it would be necessary to use a fully macroeconomic model such as MDM as a replacement to the I-O model.

Since Leontief's important work on environmental issues [13-15], I-O models have been used in the analysis of pollution, climate change, carbon mitigation technologies and impacts and costs evaluation. Such models describe the complex interrelationships amongst economic sectors using sets of simultaneous linear equations. The coefficients of these equations are fixed based on past behaviour of the economic system, which means that factor substitution, technological change, and behavioural aspects related to climate change mitigation and adaptation policies cannot be assessed directly but must be brought into the model exogenously. Still, I-O models provide considerable sectoral details on how demand for 
goods and services, and through these energy and materials, is met. Hence the model described in the current paper is demand-driven rather than supply-driven.

Additionally, I-O models have been applied to analyses of complex economies such as in the Netherlands [16-19]. Van der Veen [20] and co-authors used I-O modelling to study backward and forward linkages to illuminate the economic hotspots as a result of a hypothetical disaster, mapping those spots in terms of economic activity in the affected area which would cause most of the (indirect) losses elsewhere in the economy. Similarly, Hallegatte [11] used an Adaptive Regional I-O (ARIO) model to examine backward and forward linkages in New Orleans, identifying key economically vulnerable and recovery sectors in the Louisiana economy pre and post Katrina; the current model and paper are an extension of Hallegatte's original insights and approach.

Cole et al. [21] contributed to the development of I-O techniques applied to earthquake analysis, using social accounting matrices (SAMs) to measure the consequences of planned and unplanned economic events in small island economies. His model was constructed on the basis of past disasters, and simulative models were produced for the specific areas most prone to the impact of natural hazards. The approach offered by Cole [22] uses an event accounting matrix (EAM), whose elements correspond to the entries of the SAM. Such an EAM, also employed here to specify the sector-specific damage used in ARIO, is constructed to enable the mapping of the direct impact of the disaster onto the economic sectors, specifying how disaster-related damage appears as losses of production capacity. With the help of an EAM, a system's vulnerability and adjustments can be modelled and the results can be used to design strategies for reducing vulnerability of regions prone to natural disasters.

Okuyama et al. [23] built an I-O model with a time dimension. The resulting dynamic character of the Sequential Inter-industry Model (SIM) allows the adoption of a production chronology for various production sectors (divided between anticipatory, responsive and just-in-time modes) to model the impact of disasters, as well as recovery and reconstruction thereafter. The model is developed for both single-region and bi-regional settings (using an I-O table for two regions). The just-in-time sectors (mostly, services) are characterised by the conventional I-O equation, whereas I-O equations for anticipatory and responsive sectors are modified. The anticipatory mode (represented by agriculture and most of the manufacturing industries) provides the dependence of a current period's output on future (anticipated) output and current final demand. The production of a sector in the responsive mode (focused on the construction industry) depends on past output and current demand.

\section{The ARCADIA-ARIO Model}

Based on the balance of criteria identified in Section 2, the ARIO model was selected as the starting point for our own modelling, with modifications described later. Previous variants by other authors have been used to assess the effects of Hurricane Katrina on the economy of Louisiana [11]; to assess coastal flood risk in Copenhagen under future climate change [2]; and to assess terrestrial flood risk under future climate change in Mumbai [24].

The flow of calculations in the macroeconomic analysis of direct plus indirect losses of climate-related damage is shown in Figure 1 (focus in that figure is on the ARCADIA project, as it was the first project to which the model was applied). In that figure, the following apply.

The blue boxes inside the dashed box labelled $\mathrm{A}$ is the ARCADIA-ARIO model itself, executed for this study in MATLAB. It performs all calculations of the recovery of the London economy after a climate-related event using the percentage losses in production capacity and demand specified in the other stages of assessment noted below.

The yellow boxes labelled B are specified externally by the user based on 1) the damage functions to the production capacity assets of the individual sectors of the economy; 2) the loss of transport capacity (specified by a transport modelling team) and 3 ) decision rules concerning the allocation of recovery resources and production capacity (these can be varied by the user).

Item 1) is determined by the damage functions. Item 2) determines the loss of labour and the loss of capacity to transport goods (including exports and imports) - and their recovery-following the initial damage. The user can specify the relationship between loss of transport capacity and loss of labour and/or flow of goods, but this specification is exogenous to the model based on empirical studies of how these relationships take place. Item 3) concerns the rules by which limited resources are allocated out after an initial damaging event. These rules consider a) how production capacity, as it rebuilds, is allocated out to satisfying final demand or intermediate goods production; it is assumed that demand for intermediate goods is satisfied first, followed by demand for final goods, but the user can vary this assumption; b) how capital resources such as finance are allocated to recovery; again the user can vary this assumption by operating the model in two modes: one where production capacity builds by the exogenously specified rate mentioned previously and one where production capacity has full priority in the allocation of resources (this significantly shortens the recovery period, albeit perhaps at the expense of GDP during that recovery); and c) how labour 


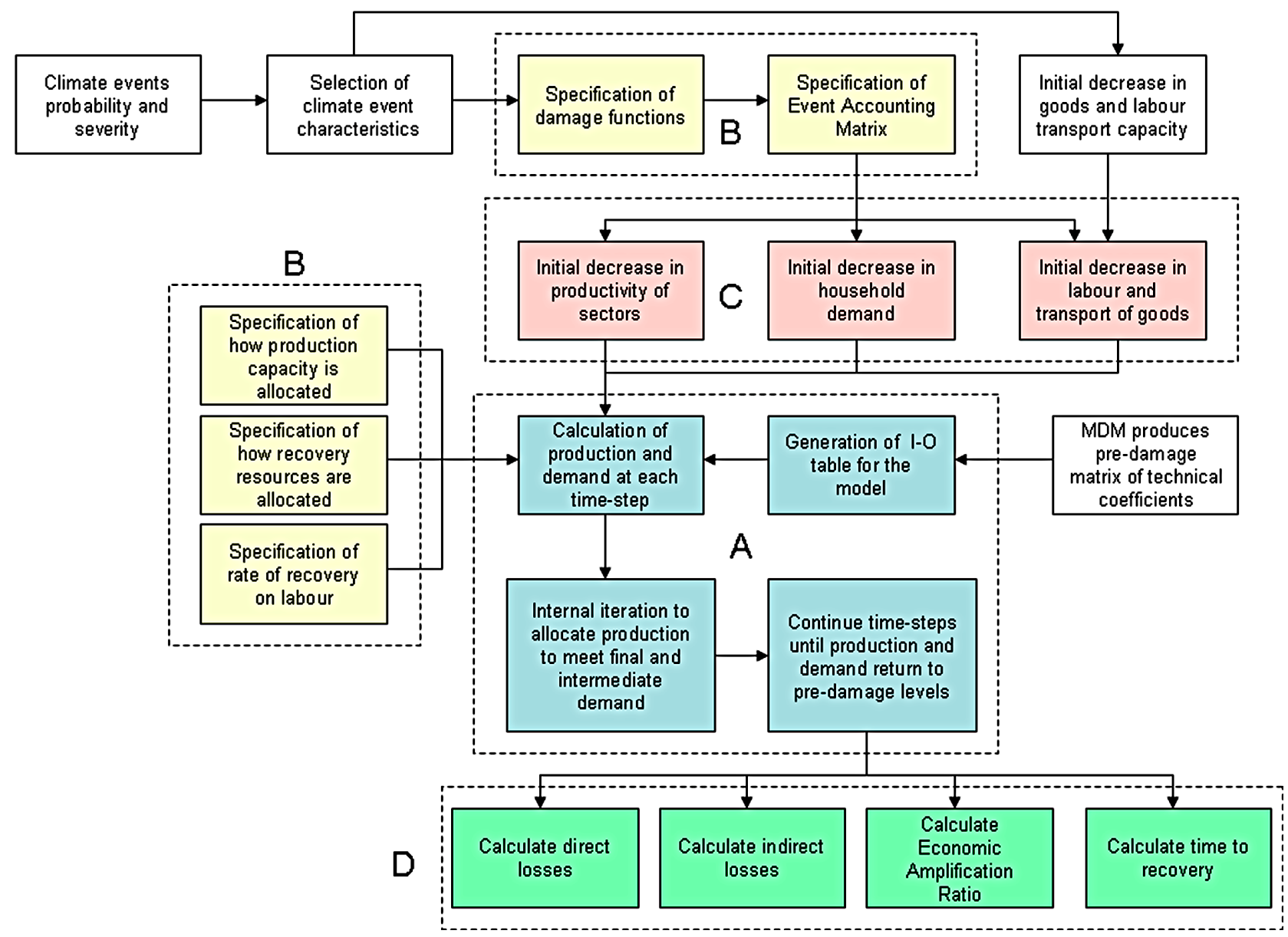

Figure 1. The flow of information and calculations endogenous within or external to the ARCADIA-ARIO model.

and the flow of goods recovers as the transport system is repaired.

The red boxes labelled $\mathrm{C}$ represent the EAM that specifies quantitatively how the initial damage from the climate event affects the sectoral production capacity, transport capacity and demand in the model. This specification is external to the ARCADIA-ARIO model.

The green boxes labelled $\mathrm{D}$ are the outputs of the model. The most significant outputs are temporal graphs of the 1) direct losses; 2) indirect losses; 3) the ratio of indirect to direct losses, from which one can calculate a multiplier effect, defined here as (indirect + direct)/(direct) and 4) the time recovery of the economy, which is a measure of resilience of an economy. To explore the issue of vulnerability in the current paper, the model is operated by replacing the EAM with a matrix in which only one economic sector at a time is reduced in production capacity, with the same percentage reduction in each sector, and the recovery period, direct losses and indirect losses calculated over the period of recovery. By repeating this process over all sectors one at a time, the user can determine which sectors make the economy most vulnerable to the same percentage loss of production capacity, reflecting both direct and indirect losses.

Figure 1 may also be related to three primary steps of calculations for climate damage and adaptation assessment:

- A step in which climate science models are used to determine climate conditions in each decade of interest, from which the probability and severity of both long-term trends (e.g. changing mean global temperature) and extreme weather events are estimated. The starting point is a probability distribution of extreme meteorological events for present and future climates from which a combination of representative events is sampled. The meteorological variables are input to models of the physical processes that cause damage e.g. hydrological and hydrodynamic flood models.

- A step in which both trends and events are translated into damage to buildings, infrastructure, stocks, labour supply and the related means of economic production.

- A step in which damage to - and hence loss of - production capacity is translated into both direct and indirect economic impacts during the recovery period.

The present paper focuses solely on this third step 
(Box A in Figure 1), recognising that the results for the first two steps will change depending on the mitigation scenarios, associated shifts in climate and extreme weather events assessed. Hence we estimate here the relative magnitude of combined direct and indirect effects on GDP in London, conditional on a given level of initial loss of production capacity in each economic sector. We do not assess here the probability or severity of specific levels of initial loss associated with specific shifts in climate, as these are outputs of the first two steps mentioned.

We organise the following discussion around the endogenous steps of calculation within the model and its external inputs. Since the model involves iterations and time-steps, the flow of calculations is not as linear as described here. However, the following organisation captures the nature of this flow of calculations, and makes it clear how information from within and outside the model is generated and used.

ARCADIA first specifies the nature of the extreme weather event. This step is carried out completely exogenous to the ARCADIA-ARIO model (in fact, this step is not reflected in the calculations of the present paper). An event is specified by the climate team from the Weather Generator of the ARCADIA project. Of central importance here is the severity of the event; e.g. the degree of flooding or the magnitude of a heatwave. The current paper does not address this step.

With the weather event specified, the initial physical damage to assets, health, services (e.g. transport), etc resulting from this extreme weather is specified. This includes damage to buildings (both commercial and household), infrastructure and health, and specifies how this damage affects production capacity, labour availability, transport of people and goods, and demand for final goods by households. This step is carried out by the engineering teams of ARCADIA, working with the economics team to ensure characterisation of initial damage is related clearly to economic sectors appearing in ARCADIA-ARIO. The current paper does not address this step.

This physical damage is then converted into economic units through the development of damage functions for each sector of the economy. The damage is in regard to production capacity in each sector and demand for final goods in the household. The units here are monetary, and are the same as those used in the calculation of GDP ( $£ /$ month, as one month is the time step of the model as described later). This step is carried out by the economics team. The current paper uses a representative but otherwise hypothetical percentage loss of production capacity in a sector, consistent with the aim of producing a sensitivity analysis that is independent of the previous steps (and hence remains valid even if those previous steps are changed).

The ARCADIA-ARIO model then calculates direct and indirect losses from time-step to time-step, using externally supplied initial conditions, parameters and recovery options (i.e. how limited resources of recovery are allocated amoungst damaged sectors). At each time-step, the current remaining level of damage is determined; the resulting demand (including demand for reconstruction) is estimated; corresponding production level is calculated for each sector, then bounded according to constraints due either to externally supplied labour constraints or the remaining current damage level to production capacity; the difference between production and internal consumption is determined; and from this the amount of damage repair occurring in the current time-step is calculated. The damage is then reduced accordingly, and the model proceeds to the next time-step.

In the following description, we use bold characters to denote both column vectors and matrices, e.g. $\boldsymbol{C} \boldsymbol{P}_{1 D}$ and A. It should be clear from context which is intended. Scalars and subscripts are not bold; subscripts may include dashes and spaces, to help readability. We also use the operators* and/to denote element-by-element operations; these may be familiar to users of software packages such as MATLAB.

\subsection{External Inputs and Parameters}

There are a number of externally provided values used by the model. Time-invariant values are:

- The technical coefficients matrix (generated using MDM, a Multi-sectoral Dynamic Model of the UK economy (Barker et al., 2001).

- Pre-disaster household, government, capital, export and import demands.

- The ratio of capital plant to productivity by sector.

- Housing stock value pre-disaster.

- The EAM, which contains damage on a sectoral basis. From this, we calculate the amounts of production capacity damage per sector resulting from the disaster, and also constraints on import capacity based on reduction in capacity of the transport sectors.

There are two pre-calculated time-series:

- Change in household demand - this is provided as a time-varying profile, reflecting the switch in consumption patterns following the modelled disaster, it being assumed that the demand for luxury goods will fall initially following the extreme weather event, with household consumption being refocused on basics and repairing household damage.

- Change in labour availability - provided as a group of time-varying profiles for daily hours delay in travelling to work, and fraction of workforce unavailable for work. 
All of the above bulleted items are common to and remain in place regardless of sector vulnerability assessed in the current study.

\subsection{Damage and Reconstruction Demand}

The key variables changing over time as the model progresses are those representing the amounts of capital and housing stock damage. Initially following the disaster, the value of capital damage by sector is calculated as follows:

1) $\boldsymbol{C} \boldsymbol{P}_{1 D}=\boldsymbol{E A M} * \boldsymbol{C} \boldsymbol{P}_{p p} *$ production $_{\text {pre-disaster }}$.

Where $\boldsymbol{C} \boldsymbol{P}_{1 D}$ is the damage to capital, $\boldsymbol{E A M}$ is the event accounting matrix of damage by sector (a column vector), $\boldsymbol{C P}_{p p}$ is the ratio of capital plant to productivity, and production $_{\text {pre-disaster }}$ is the value of pre-disaster production.

Damage to housing stock is taken to be a fraction of the pre-disaster housing stock value (an external input).

2) $h h_{\text {capitaldamage }}=h h_{\text {damagefraction }} * h h_{\text {capital predisaster }}$.

The damage levels to this stock decrease as the time steps proceed, as described later.

\subsection{The Model Equations: Calculating Unconstrained Production}

The ARCADIA ARIO model is based around a linear production-demand equation

3) $x=A x+f$

which may be rewritten as

4) $\boldsymbol{x}=\boldsymbol{L} \boldsymbol{f}$

where

5) $\boldsymbol{L}=(\boldsymbol{I}-\boldsymbol{A})^{-1}$.

Here $\boldsymbol{x}$ is a vector of production by sector, and $\boldsymbol{A}$ is a matrix of technical coefficients. Production can be calculated using the Leontief inverse, $\boldsymbol{L}$, and the summated demand vector, $\boldsymbol{f}$.

The demand vector $\boldsymbol{f}$ is made up of household, government, capital and export demand, less import demand, plus the reconstruction demand.

6) $\boldsymbol{f}=\boldsymbol{f}_{\text {hh }}+\boldsymbol{f}_{\text {gov }}+\boldsymbol{f}_{\text {cap }}+\boldsymbol{f}_{\text {exp }}-\boldsymbol{f}_{\text {imp }}+\boldsymbol{f}_{\text {recon }}$.

Of these, $\boldsymbol{f}_{h h}$ is an exogenous time-varying input; $\boldsymbol{f}_{g o v}$, $f_{\text {cap }}$ and $\boldsymbol{f}_{\exp }$ are assumed to be constant through the post-disaster recovery period; $\boldsymbol{f}_{\text {imp }}$ is assumed to be constrained, depending on the ratio of the current time-step's summated productivity for the transportation sectors to the pre-disaster summated productivity for the transportation sectors - a $10 \%$ loss in productivity for the transportation sectors therefore leads to a $10 \%$ fall in imports; $f_{\text {recon }}$ is a function of the value of damage awaiting repair.

\subsection{Calculating Reconstruction Demand from Damage}

The reconstruction demand in the model, $\boldsymbol{f}_{\text {recon }}$. is the sum of the reconstruction demands by sector across all economic sectors, plus the value of outstanding household capital damage, $\boldsymbol{\Sigma} \boldsymbol{C} \boldsymbol{P}_{1 D}+h h_{\text {capital damage. The reconstruc- }}$ tion demand is assumed to be split between six economic sectors; $50 \%$ goes to the Construction sector, and $10 \%$ to each of Mechanical Engineering, Electronics, Electrical Engineering and Instrumentation, Motor Vehicles, and Manufacturing (not elsewhere specified).

\subsection{Constraining Production}

The level of production resulting from the above calculation may be constrained, either by labour availability or by shortage of capital. The labour constraint is calculated as follows:

7) $\boldsymbol{q}_{\text {lab }}=\left(\boldsymbol{L H}_{\text {rem }} / \boldsymbol{L H}_{0}\right) *$ production $_{\text {pre-disaster }}$.

Where $\boldsymbol{q}_{l a b}$ is the labour constrained production rate, $\boldsymbol{L H}_{r e m}$ is the number of hours labour available per month post-disaster, $\boldsymbol{L H}_{0}$ is the number of hours labour available pre-disaster, and production $_{\text {pre-disaster }}$ is the level of production pre-disaster. In the model, $\boldsymbol{q}_{l a b}$ is calculated at each monthly time-step, using exogenously provided values related to labour losses and travelling restrictions.

The capital constraint is calculated as follows:

8) $\boldsymbol{q}_{C P}=\boldsymbol{C P}_{A D} / \boldsymbol{C} \boldsymbol{P}_{P P}$.

Where $\boldsymbol{q}_{C P}$ is the capital-constrained production rate, $\boldsymbol{C P}_{A D}$ is the capital remaining post-disaster by sector, and $\boldsymbol{C P}_{P P}$ is the ratio of capital plant to productivity by sector. This assumes that the relation between capital investment in a sector and the sector's productivity is fixed throughout the disaster and recovery period. The ratio $\boldsymbol{C P}_{P P}$ is obtained by dividing the pre-disaster capital levels by the pre-disaster production. In the model, the capital constraint is calculated at each monthly time-step, using that month's value for the current capital levels, which increase as recovery proceeds.

The constraint applied to production $\boldsymbol{q}_{r e m}$ is the minimum of $\boldsymbol{q}_{l a b}$ and $\boldsymbol{q}_{C P}$. This constraint forms the upper bound on production. If recovery is defined as return to the pre-disaster production levels, then the capital constrained production rate could potentially apply throughout the recovery period; however, it may be undercut by the labour constrained production rate.

\subsection{Bottlenecking}

During the recovery period, it is possible for production 
to be bottlenecked, where the level of production from a sector is insufficient to meet the economy's internal demand, $<\boldsymbol{A x}$, and so production in sectors that rely on inputs from the constrained sector has to be scaled back accordingly. Assuming un-bottlenecked pre-disaster production:

9) $\boldsymbol{x}^{0} \geq \boldsymbol{A} \boldsymbol{x}^{0}$.

Given an equal damage fraction across all sectors, we calculate the post-disaster level of production, $\boldsymbol{x}^{p d}$, from the pre-disaster level of production, $\boldsymbol{x}^{0}$, as follows. Since production is proportional to surviving capital and equal damage fractions mean equal surviving fractions:

10) $\boldsymbol{x}^{p d}=\boldsymbol{k} * \boldsymbol{x}^{0}$

Testing for bottlenecking, we have

11) $\boldsymbol{x}^{p d} \geq \boldsymbol{A} \boldsymbol{k} \boldsymbol{x}^{0}$

or, substituting for $\boldsymbol{x}^{p d}$,

12) $\boldsymbol{k} \boldsymbol{x}^{0} \geq \boldsymbol{A} \boldsymbol{k} \boldsymbol{x}^{0}$.

This clearly holds if the original production was not bottlenecked. If a non-uniform EAM is used, then bottlenecking may occur; however, the exogenous EAM used in this current paper does not cause bottlenecking. Where damage is modelled as being an equal fraction across all sectors, bottlenecking cannot happen. Similarly, the labour constraint results in equal proportions of restriction on production, and so cannot lead to bottlenecking. In the event that the model were required to describe a scenario in which bottlenecking occurs, an iterative process similar to that described in the appendix to [11] is used.

\subsection{Calculating Production Available to Meet Demand}

In the presence of a production constraint, the excess of production over local consumption internal to the economy will not be sufficient to satisfy the demand. In that case, that portion of production which exceeds the internal consumption ( $\left.\boldsymbol{x}_{\text {constrained }}-\boldsymbol{A} \boldsymbol{x}_{\text {constrained }}\right)$ is apportioned among the various components of demand in the following way:
13) $\boldsymbol{f}_{\text {hhrem }}=\left(\left(\boldsymbol{x}_{\text {constrained }}-\boldsymbol{A} \boldsymbol{x}_{\text {constrained }}\right) / \mathrm{f}\right) * \boldsymbol{f}_{h h}$

Here $\boldsymbol{f}_{h h}$ has been used as an illustration; the other components of demand are treated similarly. The reconstruction demand, $f_{\text {recon }}$, is the production going towards repairing damage caused by the disaster. It is assumed that local production is utilized to the extent available to meet demand, before the economy turns to increases in imports.

\subsection{Updating Damage Levels}

Month by month, the level of unrepaired damage falls, and the level of capital available for production increases. The reconstruction demand, $\boldsymbol{f}_{\text {recon, }}$, is made up of demand for repair of capital damage and demand for repair of housing stock. The changes in the two demands are calculated as follows:

$$
\text { 14) } \Delta \boldsymbol{C P}_{1 D}=\left(\boldsymbol{C} \boldsymbol{P}_{1 D} /\left(\boldsymbol{\Sigma} \boldsymbol{C} \boldsymbol{P}_{1 D}+h h_{\text {capitaldamage }}\right)\right) * \Sigma \boldsymbol{f}_{\text {recon }}
$$

and

15)

$$
\begin{aligned}
& \Delta h h_{\text {capitaldamage }} \\
= & \left(h h_{\text {capitaldamage }} /\left(\boldsymbol{\Sigma} \boldsymbol{C} \boldsymbol{P}_{1 D}+h h_{\text {capitaldamage }}\right)\right) * \Sigma \boldsymbol{f}_{\text {recon }} .
\end{aligned}
$$

Hence, updating at the end of a time step,

$$
\text { 16) } \boldsymbol{C P}_{1 D}(t+1)=\boldsymbol{C P}_{1 D}(t)+\Delta \boldsymbol{C} \boldsymbol{P}_{1 D}
$$

and

$$
\text { 17) } \begin{aligned}
& h h_{\text {capitaldamage }}(t+1) \\
= & h h_{\text {capitaldamage }}(t)+\Delta h h_{\text {capitaldamage }}
\end{aligned} \text {. }
$$

\subsection{The Economic Sectors}

The specific economic sectors (plus Labour) considered, specified within MDM used to generate the technical coefficients matrix for the ARCADIA-ARIO model, are shown in the table below. The table also shows an initial, hypothetical, EAM ( $10 \%$ in all sectors due to damage to assets and processes, and 20\% loss in Labour due to ad-

\begin{tabular}{|c|c|c|c|c|c|c|c|}
\hline 1 Agriculture etc & $10 \%$ & 12 Rubber \& Plastics & $10 \%$ & 23 Gas Supply & $10 \%$ & 34 Insurance & $10 \%$ \\
\hline 2 Coal & $10 \%$ & 13 Non-Met. Min. Prods. & $10 \%$ & 24 Water Supply & $10 \%$ & 35 Computing Services & $10 \%$ \\
\hline 3 Oil \& Gas etc & $10 \%$ & 14 Basic Metals & $10 \%$ & 25 Construction & $10 \%$ & 36 Prof. Services & $10 \%$ \\
\hline 4 Other Mining & $10 \%$ & 15 Metal Goods & $10 \%$ & 26 Distribution & $10 \%$ & 37 Other Bus. Services & $10 \%$ \\
\hline 5 Food, Drink \& Tob. & $10 \%$ & 16 Mech. Engineering & $10 \%$ & 27 Retailing & $10 \%$ & 38 Public Admin. \& Def. & $10 \%$ \\
\hline 6 Text. Cloth. \& Tob. & $10 \%$ & 17 Electronics & $10 \%$ & 28 Hotels \& Catering & $10 \%$ & 39 Education & $10 \%$ \\
\hline 7 Wood \& Paper & $10 \%$ & 18 Elec. Eng. \& Instrum. & $10 \%$ & 29 Land Transport etc & $10 \%$ & 40 Health \& Social Work & $10 \%$ \\
\hline 8 Printing \& Publishing & $10 \%$ & 19 Motor Vehicles & $10 \%$ & 30 Water Transport & $10 \%$ & 41 Misc. Services & $10 \%$ \\
\hline 9 Manuf. Fuels & $10 \%$ & 20 Oth. Transp. Equip. & $10 \%$ & 31 Air Transport & $10 \%$ & 42 Unallocated & $10 \%$ \\
\hline 10 Pharmaceuticals & $10 \%$ & 21 Manuf. Nes & $10 \%$ & 32 Communications & $10 \%$ & 43 Labour & $10 \%$ \\
\hline 11 Chemicals nes & $10 \%$ & 22 Electricity & $10 \%$ & 33 Banking \& Finance & $10 \%$ & & $10 \%$ \\
\hline
\end{tabular}
ditional transportation damage and other disruptions preventing workers from travelling to their workplace, for example because they have to repair their homes or look after inconvenienced relatives). 
The I-O tables are obtained from MDM [25]. These tables do not, however, contain capital assets data. In order to identify the available and damage capitals discussed previously, the model is created on the following steps:

- Sectoral capital availability for the period of 19922008 in the UK was obtained, and a linear projection to 2018-2020 was conducted (2020 being the most future-reaching structure of the economy considered in the analyses for this paper).

- Sectoral capital productivity for the UK as a whole (capital/total output) was obtained. Then, by employing the total output in London, available industrial capital for the London area (official statistics for capitals in London are not available) was estimated.

- Household capital for the period of 1992-2008 in the UK was obtained, and a linear projection to 20182020 was conducted.

- Official statistics reveal that London hosts $14 \%$ of households in the UK. We assume that the capital assets in London account for 14\% of overall household assets in the UK. The assumption here is that every household's capital assets in London have the same value to UK average (one may work out the real capital assets in London by using real estate data, but this correction has not been performed to date).

Due to the absence of inter-regional trade data and the generally poor quality of regional data, a model of the regional economies of the UK with significant economic content inevitably entails a substantial exercise in data construction. Some considerable reduction of data requirements on inter-regional trade has therefore been made for the current model. The treatment of inter-regional trade in the MDM model follows Leontief's approach [13], elaborated further by Leontief and Strout [14], which assumes that each industry had the same cost structure in each region, that commodities were either entirely locally produced and consumed or traded, and that the traded commodities were traded in fixed proportions to total output.

\subsection{The Process of Adjustment after Initial Damage}

There is flexibility (both in reality and in the ARIO model described) in how the limited production capacity is to be allocated out to intermediate and final goods during the period of recovery. This specification is a critical point at which the approaches of Hallegatte [10, 11,26] and Steenge and Bočkarjova [27] differ in developing their versions of the I-O models for post-disaster recovery. Steenge and Bočkarjova argued that a disproportioned economy following a disaster will require an economic adjustment process to re-balance itself before it can grow further according to von Neumann balanced growth theory. The implication is that the disaster may change the flow of goods and services for some period of time, but a deeper structural change in the economy will not occur. They further argued that the economic recovery following a disaster happens in two steps: first the economy adjusts itself in terms of fixed (pre-disaster) industrial output apportionments with no change in the relative degree of activity in each sector. The economy will then grow again towards the level of economic output in the pre-disaster condition, with all sectors growing proportionately at the same rate.

By contrast, the economic adjustment process is quite different in the approach of Hallegatte. If an industry cannot satisfy total demand post-disaster, its production goes first to satisfying intermediate consumption from other industries. All industries are assumed equally rationed: what an industry gets is proportional to what it ordered pre-disaster. The ARCADIA-ARIO model allows for a mix of a priority system and proportional rationing, where the relative degree of economic activity in different sectors (compared against the pre-disaster activities) may change for some period of time. However the aim of the rationing scheme is usually to allow the economy to return to its pre-disaster condition, which then will be built on for further economic development. In the model used in the current paper, each industrial sector is individually rationed to allow the economic production structure to return to the pre-disaster conditions. The main advantage of this approach is that it is built on strong economic development theory and always allows the economy to develop into the most economically efficient structure (believed to be that which was in place before the disaster).

When industry $i$ has limited capacity insufficient to fulfil the full demand required by both intermediate and final consumption, the rationing scheme prioritises the destination of the commodity produced by $i$. Priority is given to intermediate demand over final demand. This assumption is justified because relationships between businesses are usually deeper than those between businesses and primary consumers, and a business will favour business clients over household clients. In addition, it is likely that policy interventions will favour these same business to business relationships in order to ensure the most rapid recovery of the production chains. The model user can specify how this allocation process takes place within the economy.

\section{Representative Results}

The ARCADIA-ARIO model has been applied to the calculation of direct and indirect effects, the ratio of these, and the recovery time, in the case of initial damage 
to production capacity and labour within the individual sectors of London's economy. The intent here is to explore the vulnerability of London's economy to various levels of damage from climate-related events impacting on all sectors simultaneously, and to the same level of damage occurring in different economic sectors individually and independently. Hence the results here represent a form of local sensitivity analysis. This analysis does not apply to any specific extreme weather event generated in the step at the upper left corner of Figure 1, but rather to a unit of damage to production capacity introduced into one or more of the economic sectors (defined by a fraction of production capacity lost initially through the damage caused by the extreme weather event).

Figure 2 displays the recovery of demand and production for the case of an initial damage equal to approximately $10 \%$ of the pre-disaster production and demand occurring in all sectors simultaneously (i.e. uniform damage throughout the sectors), with the exception of labour where the reduction is initially $20 \%$ due to transport system losses. The green line shows the change in demand over time, and the red line shows the change in production. Note first that recovery of both production and demand is complete by between 10 and 15 months, and that they are balanced by the end of this period. The demand remains above production throughout the recovery period, as damage is repaired.
Figure 3 shows the influence of magnitude of initial damage (again, applied equally across all production sectors) on the recovery time. In this figure, the damage fraction is the fractional damage to production capacity uniformly applied across sectors simultaneously. Note the significant increase in recovery time as the scale of initial damage increases.

Figure 4 shows the ratio of indirect losses over direct losses (from which the multiplication factor as defined previously can be calculated), as a function of direct losses to assets associated with production capacity (the assumption here being that production capacity loss in a sector is proportional to asset loss). This ratio is less than one up to approximately $£ 75 \mathrm{~B}$ (\$100B), and then the indirect losses dominate total economic impacts. However, the values on the graph past $£ 200 \mathrm{~B}$ represent levels of damage that would be likely to causes shifts in the structure of the local economy, a scenario for which ARCADIA-ARIO is not suited. As a result, values of the ratio larger than 2 or 3 are not of interest here.

The analyses above assume that recovery of production is demand-led; i.e. that an asset owner increases production capacity only as demand rises. This means the speed of recovery is limited by the most slowly recovering sector of the economy. By contrast, we consider something more akin to a government-led recovery in which resources for recovery are utilised even in advance

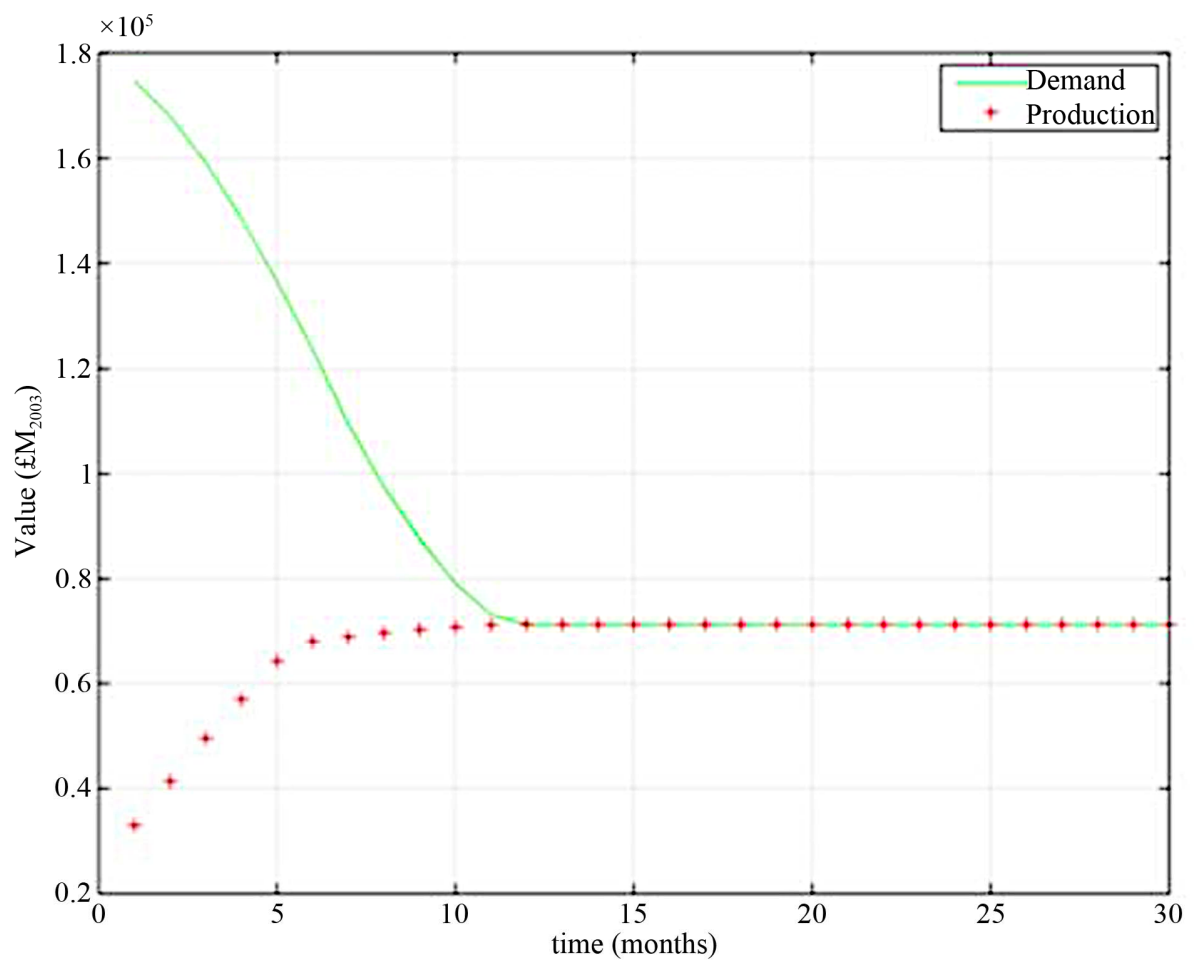

Figure 2. Temporal recovery of production and demand in London's economy following an initial damage of approximately $10 \%$ of pre-disaster production, and initial $20 \%$ reduction in Labour. The initial increase in demand relative to pre-damage levels is driven by reconstruction after the event. 


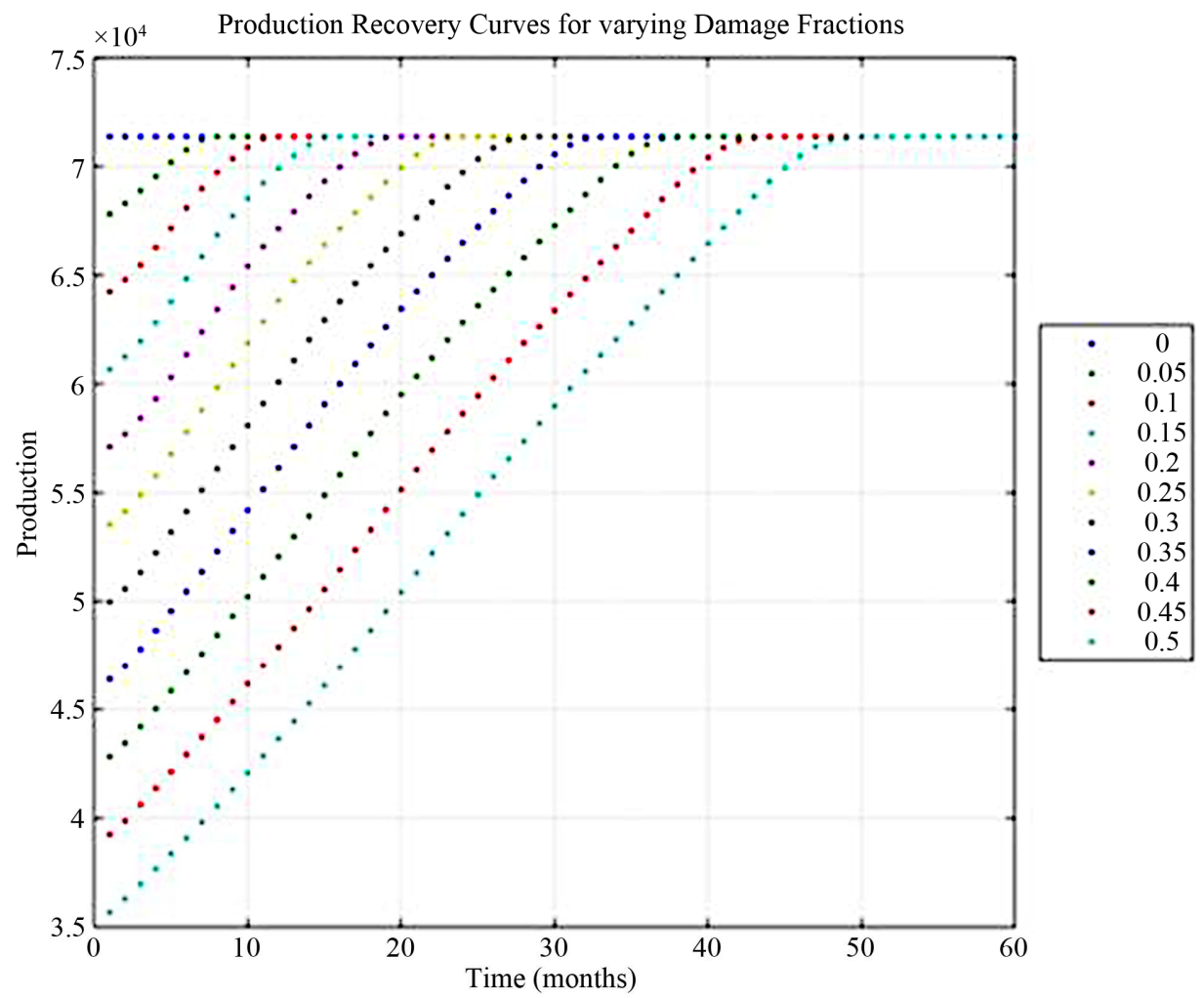

Figure 3. Plots of recovery of production versus time for a range of damage fractions.

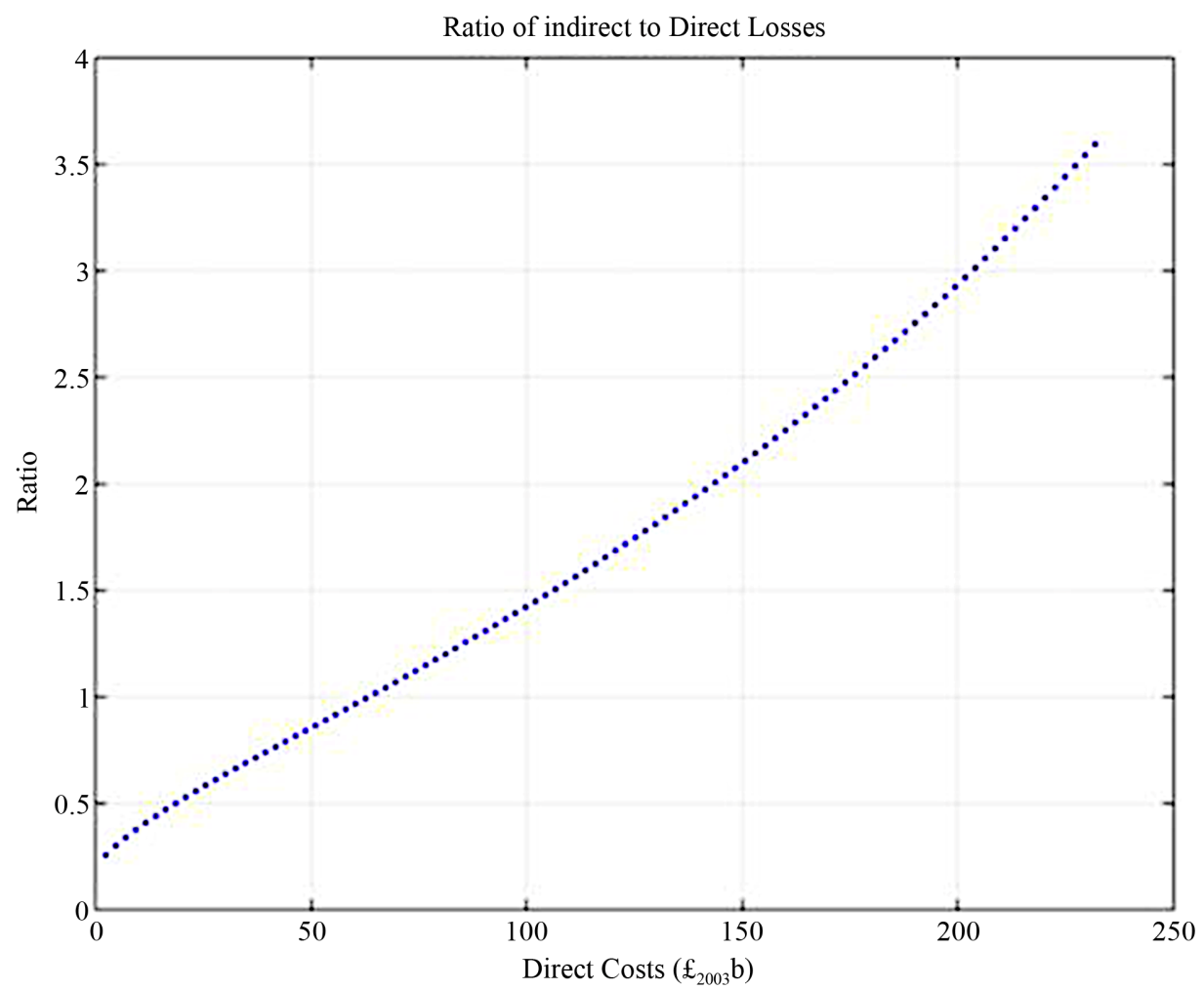

Figure 4. Indirect/Direct losses as a function of direct losses when all sectors experience the same fractional loss in production capacity as a result of the extreme weather event. In this analysis, damage to the transport infrastructure is held constant to allow for assessment of vulnerability of the economy to only direct loss of production capacity. Hence, the indirect losses do not go to zero as the direct costs go to zero in this figure. 
of demand, with the goal of recovering production capacity as rapidly as possible. Figure 5 shows the influence of these two assumptions. Note the significant difference in recovery time under these two assumptions, with the recovery time being roughly halved when the latter assumption is used. This shows the important influence of replacing or repairing production capacity in advance of the recovery of demand.

Finally, we consider in Figure 6 the vulnerability of London's economy, in terms of indirect losses, to an equal amount of damage in each of the different sectors placed into only one sector at a time.

We then repeat the analysis of Figure 6, but using Recovery Time as the measure of resilience. Results are shown in Figure 7.

\section{Conclusions and Discussion}

Methodology has been developed to understand the indirect economic impacts of climate-related disasters, using London as a case study and building on work reported by Dawson et al. [28], Hall et al. [29] and Walsh et al. [30] placing climate change and adaptation into a probabilistic, risk-based framework. Following previous researchers, an Input-Output model has been adopted, and modified incorporate the direct damage to capital, the interruption of labour and the effects on final and intermediate demands of disasters and the recovery period. The method- ology is intended to form part of a broader risk analysis framework which samples a population of extreme meteorological events representative of present and future climatic conditions. In this way, the research is intended to provide economic estimates of climate risks, which will inform the allocation of investments in adaptation and help to target adaptation planning.

The results show that for a range of simulated events of differing severity, the indirect losses from damaging events can be of the order of 1.3 to 2 times the direct losses. The results also identify the most vulnerable sectors of the economy.

The results display several consistent conclusions across the various figures. Both the analysis of the indirect/direct ratio in Figure 4 and the full analysis of GDP loss with damage placed one sector at a time into the model in Figure 6, show that sectors 26 (Distribution) and 36 (Professional Services) dominate with respect to vulnerability of the London economy, with sector 29 (Land Transport) also being significant, as might be expected due to impacts on Distribution and Labour. In regard to reduced vulnerability, conditional on equal fractional damage to production capacity being induced in all sectors by an extreme weather event, adaptation strategies that either reduce the damage inflicted on sectors 26 or 36 , or that improve recovery in those sectors, will reduce the vulnerability of London's economy. The full

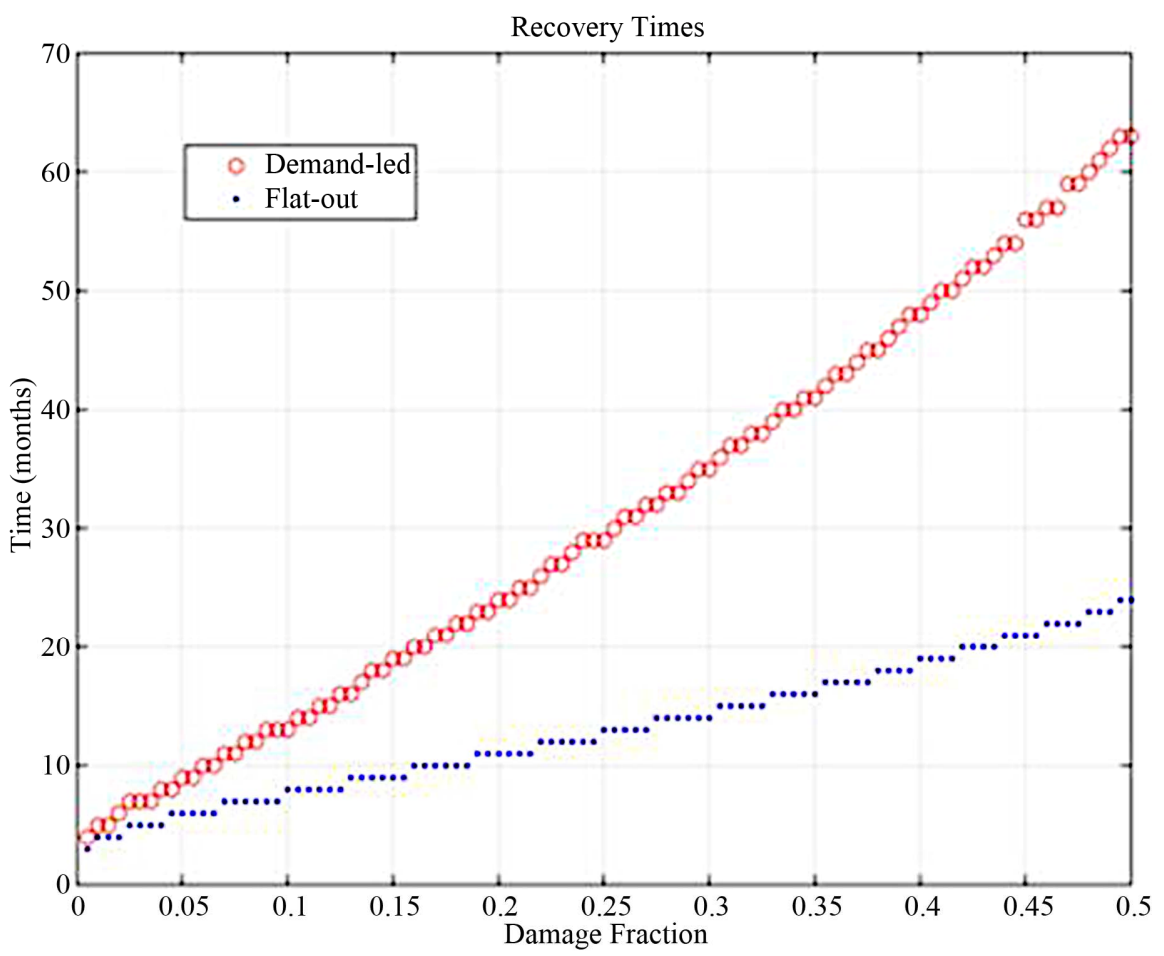

Figure 5. Recovery time for the economy under the demand-led assumptions of earlier figures in this section (red line) and assuming resources are devoted to recovery of production capacity in advance of demand (blue line, called "flat out"). The $x$ axis is the fractional initial damage to production capacity due to the extreme weather event. 


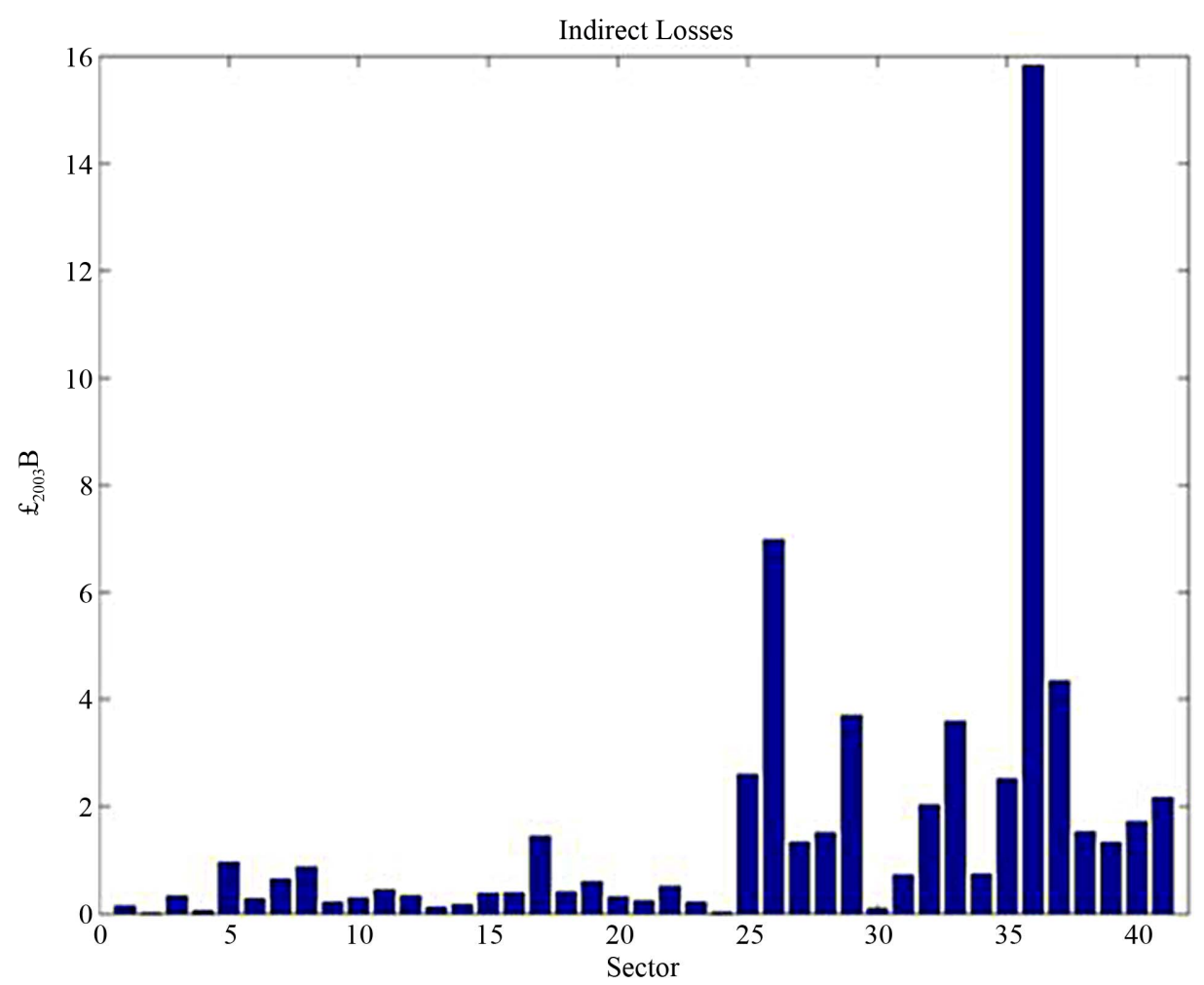

Figure 6. The relative vulnerability of London's economy, in terms of indirect losses, to the same fractional change in production in each of the 42 sectors considered in the model, when that damage occurs in only one sector at a time, all other sectors being undamaged. These sectors are described in the table previously. For reference, sector 36 is Professional Services and sector 26 is Distribution.

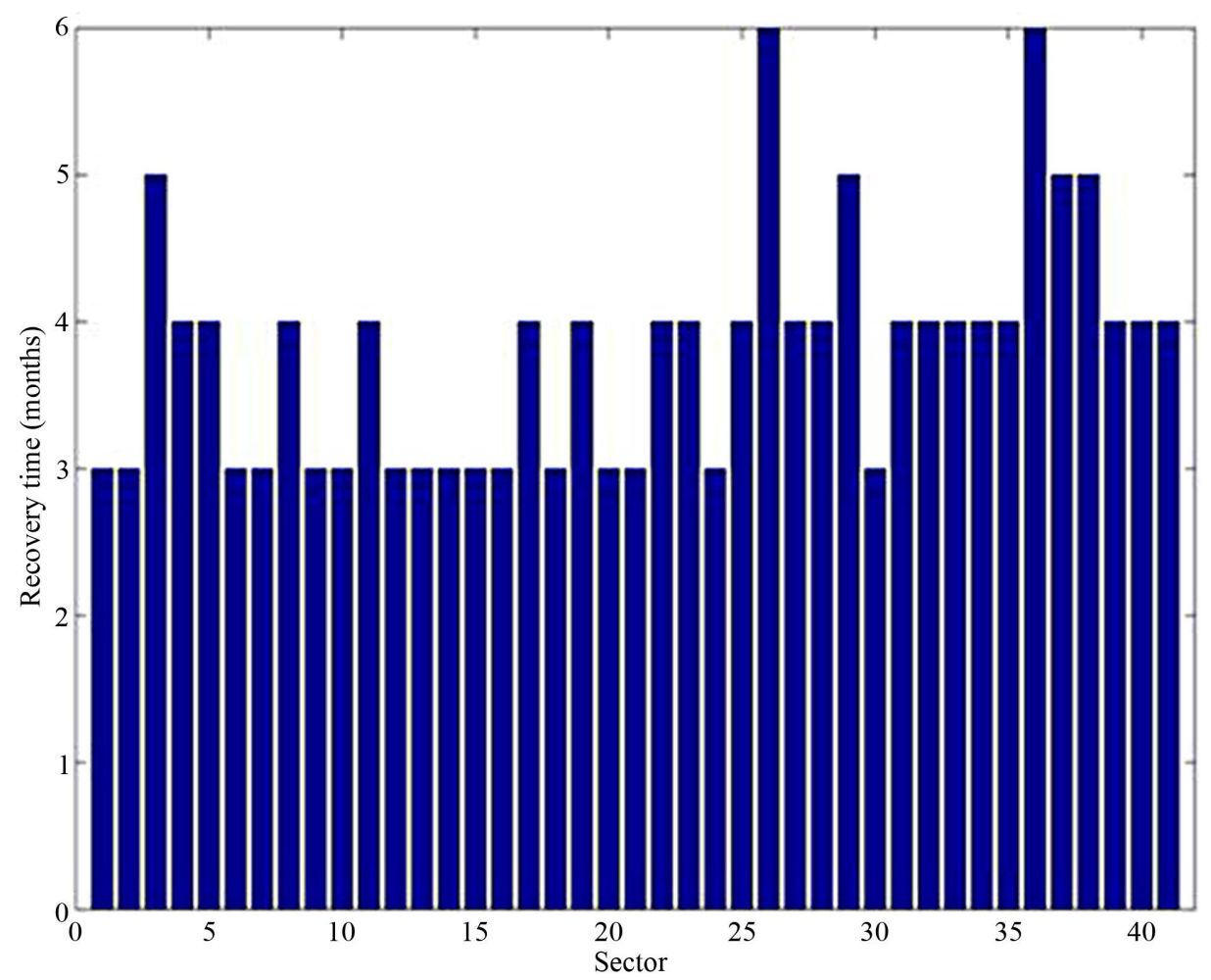

Figure 7. The relative resilience of London's economy, as measured by recovery time, to the same fractional damage in each of the 42 sectors considered in the model. These sectors are the same as in Figure 6. 
analysis of Recovery Period in Figure 7 additionally shows sectors 3 (Oil and Gas), 37 (Other Business Services) and 38 (Public Administration and Defence) as playing significant roles in the time required for production and demand to return to pre-disaster conditions. These findings are consistent with London having a strong services economy, including financial services, and being the seat of national government. Again, limited adaptation and/or recovery resources might be directed towards these additional sectors as a second-priority adaptation strategy.

Note from Figure 2 that demand in the London economy is quite strong post-disaster until recovery is complete, driven by demand for goods and services associated with recovery activities. Much of this demand, however, is being unmet due to the loss of production capacity; the recovery period will therefore depend critically on the availability of increased imports of recovery-related goods and services. That unmet demand declines to zero during the recovery period, although this takes slightly longer than the return of production capacity due to continuing unmet demand for household recovery.

Figure 3 shows the relationship between scale of initial damage and recovery period. At the level of 0.05 fractional damage to production capacity (a medium storm that might strike London once every few decades), recovery is complete within a year. For damages of the scale of Hurricane Katrina in New Orleans (e.g. a storm that might strike London once a century), the recovery period is 3 to 4 years. Values of the damage function beyond 0.5 (a $50 \%$ initial loss of production capacity) are not simulated here because these are likely to be accompanied by a large-scale change in the structure of London's economy (as was true in New Orleans), and so the assumptions of an I-O model will be invalidated due to the change in the technical coefficients.

As seen in Figure 4, the ratio of indirect over direct losses is less than 1 (or a multiplier effect of less than 2 as defined in section 3 ) for small to moderate damage, up to $\$ 75 \mathrm{~B}$. Beyond initial damages of $£ 200 \mathrm{~B}$, the ratio rises as high as 4 to 5 , but these are scales of damage that would probably be accompanied by significant shifts in the structure of London's economy (e.g. the financial services sector moving operations elsewhere), shifts that invalidate the use of the same technical coefficients matrix. It is more reasonable to conclude that the ratio is somewhere in the region of 0.3 to 2 for the larger damages for which ARCADIA-ARIO is suitable, which is a multiplication factor (as defined earlier) of 1.3 to 3 . This is consistent with the literature (cited earlier) suggesting that indirect losses can be a significant component of total economic damage following extreme climate events.

Finally, Figure 5 shows the influence of changing the dynamics of recovery by introducing social mechanisms for funding recovery of production capacity in advance of demand. It is evident that the length of the recovery period can be significantly shortened by so directing resources, rather than letting production rise only in response to demand through the operation of the market. Since this re-direction of resources will probably require government intervention and investment, the important role of government in reducing vulnerability and increasing resilience of an economy is suggested. The result would be a more supply-driven recovery.

The limitations of these conclusions should be understood in the context of using an I-O model as the basis for estimating indirect losses. As described earlier, an I-O approach has the advantage of being less computationally intensive than fully dynamic macroeconometric models, and being able to incorporate externally-derived damage and recovery processes that are driven as much by non-economic considerations (e.g. engineering feasibility) as economic considerations by key actors. These actors will in part allocate out recovery resources in ways consistent with economic theory, but they are also driven by concerns for customer loyalty, corporate social responsibility, asset risk reduction, planning requirements, availability of structural engineers, and the dynamics of repair, replacement and new capital investment cycles. By specifying many of the model features externally, ARCADIA-ARIO allows for maximal use of information from the other components of the ARCADIA project that reflect the engineering and governance of the built environment in London.

Still, use of the ARCADIA-ARIO model, with the inherent assumption of a stable technical coefficients matrix taken from pre-disaster conditions, prevents the modelling of processes that might be affected by price changes during the recovery period. As just one of many possible examples, damage to the transportation system affects availability of imports within the model; the model can also in suitable form reflect changes in export capacity through modification of the EAM. In reality, it is likely that this damage will cause a shift to other means of transport of goods, entailing changing prices of transport and of the transported goods while an attempt is made to meet all demand (both internally and in communities to which goods are exported) during recovery. This is a problem in which use of the dynamic econometric model (e.g. MDM) would be a possible solution, albeit at significantly increased computational and data requirements.

\section{Acknowledgements}

The authors acknowledge the Three Guineas Trust and the EPSRC (through the ARCADIA project in with Prof Hall is PI) for providing significant support for the work 
reported here. The research was undertaken as part of the project ARCADIA: Adaptation and Resilience in Cities: Analysis and Decision making using Integrated Assessment, which was funded by the UK Engineering and Physical Sciences Research Council under grant EP/ G061254/1.

\section{REFERENCES}

[1] J. Albala-Bertrand, "Political Economy of Large Natural Disasters," Oxford University Press, Oxford, 1993.

[2] S. Hallegatte, F. Henriet and J. Corfee-Morlot, "The Economics of Climate Change Impacts and Policy Benefits at City Scale: A Conceptual Framework," Climatic Change, Vol. 104, No. 1, 2011, pp. 51-87. doi:10.1007/s10584-010-9976-5

[3] I. Azis, "Exploring Economy-Wide Impacts of Climate Change in a Resource-Rich Country," Annual International Seminar on Macroeconomic Impact of Climate Change: Opportunities and Challenges, Conference Paper, Bali, 1-2 August 2008.

[4] R. Miller and P. Blair, "Input-Output Analysis: Foundations and Extensions," Cambridge University Press, Cambridge, 2009. doi:10.1017/CBO9780511626982

[5] O. Karkacier and Z. Goktolga, "Input-Output Analysis of Energy Use in Agriculture," Energy Conversion and Management, Vol. 46, No. 9-10, 2005, pp. 1513-1521. doi:10.1016/j.enconman.2004.07.011

[6] S. Cole, "Protection, Risk, and Disaster in Economic Networks," In Search of a Common Methodology on Damage Estimation, Joint NEDIES and University of Twente Workshop Proceedings, Office for Official Publications of the European Communities, Delft, 2003.

[7] A. Rose and S. Liao, "Modeling Regional Economic Resilience to Disasters: A Computable General Equilibrium Analysis of Water Service Disruptions," Journal of Regional Science, Vol. 45, 2005, pp. 75-112. doi:10.1111/j.0022-4146.2005.00365.x

[8] A. Rose, "Defining and Measuring Economic Resilience to Disasters," Disaster Prevention and Management, Vol. 13, No. 4, 2004, pp. 307-314. doi: $10.1108 / 09653560410556528$

[9] H. Cochrane, "Economic Loss: Myth and Measurement," In Search of a Common Methodology on Damage Estimation, Joint NEDIES and University of Twente Workshop Proceedings, Office for Official Publications of the European Communities, Delft, 2003.

[10] S. Hallegatte, J.-C. Hourcadec and P. Dumasc, "Why Economic Dynamics Matter in Assessing Climate Change Damages: Illustration on Extreme Events," Ecological Economics, Vol. 62, No. 2, 2007, pp. 330-340. doi:10.1016/i.ecolecon.2006.06.006

[11] S. Hallegatte, "An Adaptive Regional Input-Output Model and Its Application to the Assessment of the Economic Cost of Katrina," Risk Analysis, Vol. 28, 2008, pp. 779-799. doi:10.1111/j.1539-6924.2008.01046.x

[12] N. Yamano, Y. Kajitani and Y. Shumuta, "Modeling the
Regional Economic Loss of Natural Disasters: The Search for Economic Hotspots," Economic Systems Research, Vol. 19, No. 2, 2007, pp. 163-181. doi:10.1080/09535310701330191

[13] W. Leontief, "Domestic Production and Foreign Trade: The American Capital Position Re-Examined," Economica Internazionale, Vol. 7, 1953, p. 3.

[14] W. Leontief and A. Strout, "Multi-Regional Input-Output Analysis," In: T. Barna, Ed., Structural Interdependence and Economic Development, St Martins Press, London, 1963, pp. 243-259.

[15] W. Leontief, "Environmental Repercussions and the Economic Structure: An Input-Output Approach," Review of Economic Statistics, Vol. 52, No. 3, 1970, pp. 262-277. doi: $10.2307 / 1926294$

[16] A. Idenburg and H. Wilting, "DIMITRI: A Dynamic Input-Output Model to Study the Impacts of Technology Related Innovations," The WIII International Conference on Input-Output Techniques, University of Macerata, Italy, 21-25 August 2000.

[17] A. Idenburg and H. Wilting, "DIMITRI: A Model for the Study of Policy Issues in Relation to the Economy, Technology and the Environment," In: J. C. J. M. van den Bergh and M. A. Janssen, Eds., Economics of Industrial Ecology: Materials, Structural Change and Spatial Scales, MIT Press, Cambridge, 2004, pp. 223-252.

[18] H. Wilting, A. Faber and A. Idenburg, "Exploring Technology Scenarios with an Input-Output Model," The International Conference on Input-Output and General Equilibrium: Data, Modelling and Policy Analysis, Brussels, 2-4 September 2004.

[19] C. Brink and A. Idenburg, "Cost-Effective Pollution Abatement in an Input-Output Model," Netherlands Environmental Assessment Agency, Unpublished Report, 2007.

[20] A. Van der Veen, "Disasters and Economic Damage: Macro, Meso and Micro Approaches," Disaster Prevention and Management, Vol. 13, No. 4, 2004, pp. 274-279. doi:10.1108/09653560410556483

[21] S. Cole, E. Pantoja and V. Razak, "Social Accounting for Disaster Preparedness and Recovery Planning," NCEER, Buffalo, 1993.

[22] S. Cole, "Lifeline and Lvelihood: A Social Accounting Matrix Approach to Calamity Preparedness," Journal of Contingencies and Crisis Management, Vol. 3, No. 4, 1995 , pp. 228-240.

doi:10.1111/j.1468-5973.1995.tb00102.x

[23] Y. Okuyama, "Measuring Economic Impacts of Natural Disasters: Application of Sequential Inter-Industry Model (SIM)," Regional Research Institute, West Virginia University, 2002.

[24] N. Ranger, S. Hallegatte, S. Bhattacharya, M. Bachu, S. Priya, K. Dhore, F. Rafique, P. Mathur, N. Naville, F. Henriet, C. Herweijer, S. Pohit and J. Corfee-Morlot, "An Assessment of the Potential Impact of Climate Change on Flood Risk in Mumbai," Climatic Change, Vol. 104, No. 1, 2011, pp. 139-167. doi:10.1007/s10584-010-9979-2

[25] T. Barker, B. Fingleton, K. Homenidou and R. Lewney, "The Regional Cambridge Multi-Sectoral Dynamic Mo- 
del of the UK Economy," In: G. Clarke and M. Madden, Eds., Regional Science in Business, Springer-Verlag, Heidelberg, pp. 79-96, 2001.

[26] Hallegatte, S., "A Dynamical Approach to the Macroeconomic Consequences of Extreme Events in a Climate Change Context," Centre International de Researche sur L-Environnment et le Developpement, 2005.

[27] A. Steenge and M. Bočkarjova, "Thinking about Imbalances in Post-Catastrophe Economies: An Input-Output Based Proposition," Economic Systems Research, Vol. 19, No. 2, 2007, pp. 205-223. doi:10.1080/09535310701330308

[28] R. Dawson, J. Hall, S. Barr, M. Batty, A. Bristow, S. Carney, A. Dagoumas, S. Evans, A. C. Ford, J. Köhler, M. R. Tight, C. L. Walsh, H. Watters and A. Zanni, "A Blueprint for the Integrated Assessment of Climate Change in Cities," In: K. Tang, Ed., Green Citynomics. The Urban
War against Climate Change, Greenleaf Publishing, Sheffield, 2009, pp. 32-52.

doi:10.9774/GLEAF.978-1-909493-88-9 4

[29] J. Hall, R. Dawson, S. Barr, M. Batty, A. Bristow, S. Carney, A. Dagoumas, A. Ford, C. Harpham, M. Tight, C. Walsh, H. Watters and A. Zanni," City-Scale Integrated Assessment of Climate Impacts, Adaptation and Mitigation," In: R. K. Bose, Ed., Energy Efficient Cities: Assessment Tools and Benchmarking Practices, World Bank, Washington DC, 2010, pp. 43-64.

[30] C. Walsh, R. Dawson, J. Hall, S. Barr, M. Batty, A. Bristow, S. Carney, A. Dagoumas, A. Alistair Ford, C. Harpham, M. Tight, H. Watters and A. Zanni, "Assessment of Climate Change Mitigation and Adaptation in Cities," Urban Design and Planning, Vol. 164, No. 2, 2011, pp. 75-84. doi:10.1680/udap.2011.164.2.75 